\title{
La formación del ciudadano desde la hermenéutica de lo ausente
}

\author{
Norma Leticia Rodríguez VázQUez \\ Universidad Pedagógica del Estado de Chihuahua \\ Campus Nuevo Casas Grandes
}

\section{Resumen \\ l interés central de este documen- 1 to es destacar la importancia en la interpretación que al interior} del ámbito educativo se requiere para llegar a detectar factores que en un determinado proceso como la formación de ciudadanos, son invisibilizados desde intereses determinados. El planteamiento radica en hacer análisis de la realidad en la que los ciudadanos de los grupos sociales asumen como natural determinada forma de vida en la que de manera generalizada se observan relaciones de inequidad. Grupos dominantes y grupos convertidos en objeto de la dominación.

Se analiza la importancia de asumir una actitud hermenéutica que logre llevar a la visibilidad los factores que en el proceso de formación del ciudadano han sido invisibilizados por intereses y permanecen en la ausencia, hasta un posicionamiento en la tradición que avala las subjetividades e intersubjetividades que rodean al sujeto.

Para esto se plantea el arribo a la interpretación desde la hermenéutica de lo ausente sustentada en teorías de pensadores como Walter Benjamin, Manuel Reyes Mate y Ricardo Forster. Emanando de allí como categorías principales: el lenguaje y sus diferentes acepciones como el silencio, a veces único refugio de los marginados, el gesto, proyección del ahogo de las palabras y la huella que sin intención de existir es parte de la realidad.

El estudio destaca la importancia categorial que permite el desocultamiento estudiado por Heidegger como aletheia, es decir, llevar las cosas a su estado de descubiertas, perfilando así posibilidades de mejores sistemas de relaciones y construcción de alteridad.

Palabras clave: ciudadano, invisibilidad, hermenéutica, ausente, lenguaje. 
La constitución del hombre como sujeto moral se produce en una relación intersubjetiva, en una aproximación al otro. Y en esa aproximación adquiere su dignidad de sujeto.

La ética compasiva. Reyes Mate (2010).

La construcción de alteridad concebida como la preeminencia por el otro, implica sin duda el análisis e interpretación de las subjetividades que constituyen la esencia del sujeto moral como ciudadano del grupo social de un contexto determinado.

Habrá que centrar la mirada en esas intersubjetividades que en ocasiones no son tomadas en cuenta o se piensan como poco importantes, limitando la posibilidad de un acercamiento entre los sujetos que se construyen como ciudadanos. Mirarlas representa ya una proximidad, situación propicia para construir alteridad y por ende esa dignidad derivada en un mejor ciudadano ocupado por el otro.

Pensar la realidad de la sociedad contemporánea obliga a mirar ese entramado que se traduce en formas de vida. Entramado político que implica hacer política del existenciario y convertirla después en las políticas públicas que impactan a los sujetos como los factores que determinan la construcción cultural que define a los ciudadanos y se convierte en el reflejo de quiénes somos como sociedad.

Esto emana de la formación adquirida a lo largo del proceso educativo, en el que los sujetos se convierten en el reflejo de la educación y los modelos pedagógicos vividos en el contexto social. De ahí la necesidad de pensar en una pedagogía que pondere al sujeto. Apoyada con una postura herme- néutica que interprete los fenómenos sociales desde las ausencias que se traducen en la piedra angular que sostiene al propio fenómeno.

Reflexionar sobre esa amalgama que se convierte en la constitución de saberes en la estructura social y sus problemáticas - que desde sus características determina la gradualidad de sus propias complejidades - requiere un alto en el camino para pensar que desde perspectivas filosóficas se podrían encontrar alternativas para interpretar cada uno de los fenómenos sociales que transcurren en ocasiones vistos como si resultaran poco importantes, dificultando la concientización de lo que nos falta por saber y pudiera convertirse en la base para detonar soluciones en términos de una formación para los ciudadanos.

Comprender una cultura es comprenderla a través de eso que queda allí, como el costado, como poco importante. [...] No se comprende una sociedad abordándola desde sus líneas maestras, universales, sus evidencias, sino a través de esas zonas menores, oscurecidas, en sombras (Forster, 2012).

La cultura creada por cada grupo social se convierte en el ámbito que determina el perfil de los ciudadanos que lo habitan, lo que muestra será siempre lo que las sociedades avalan como lo verdadero en ella, sin embargo, una postura filosófica apoyada en un proceso hermenéutico de interpretación podría ser el inicio hacia el análisis de factores que han sido invisibilizados y permanecen ausentes en lo mostrado.

Los constructos epistemológicos se piensan de manera recurrente como los 
que hacen de esta sociedad la división en los grupos que la conforman, se piensa socialmente en los que de alguna manera se convierten en esencia de poder y los que representan a los que viven en estado de vulnerabilidad y desprotección en los diferentes rubros socioeconómicos, tal división se concibe como parte de los conocimientos que como sociedad establecemos a través de la educación.

La hermenéutica despliega una serie de posibilidades para detectar lo que en los fenómenos no se encuentra a simple vista, es decir, vista como la tradición que contiene las capacidades críticas para interpretar un contexto determinado, como lo que en ese entramado social se entreteje con factores determinantes que permanecen ocultos tras una palabra, un gesto o una huella perdida en el tiempo, se han convertido en categorías de investigación y derivado en la construcción de la hermenéutica de lo ausente para arribar a la comprensión de estructuras y fenómenos sociales de la actualidad.

Planteo entonces - la hermenéutica de lo ausente- como el sendero de una interpretación que acerque sus resultados a la realidad de fenómenos sociales. Surge en el estudio, el lenguaje como una categoría de primer orden por ser considerado el sujeto mismo y desde allí encontrarlo en su discurso. "El ser espiritual se comunica en y no a través de la lengua" (Benjamin 2012:141).

El lenguaje analizado sin confines, en sus diferentes acepciones; el silencio, proyección a veces de los llamados "nadies" por Eduardo Galeano, como el único re- ducto de refugio. El gesto que muestra en ocasiones lo que la palabra ahoga. O la huella, que sin ninguna intención de existir es parte de la realidad.

Vistas así las cosas, el lenguaje permite mirar al ser desde allí, como una y la misma cosa y no como algo separado.

El problema hermenéutico sobre la interpretación de lo ausente, requiere una profunda reflexión que derive en la elección de las formas interpretativas que más acerquen a la realidad de las situaciones no miradas a simple vista, de los factores ausentes, ocultos detrás de un discurso que pareciera ocupado por formar mejores ciudadanos.

El lenguaje proyecta lo implícito y no visto, lo que permanece ausente, finalmente reviste importancia tal que puede ser el conducto hacia determinada tradición. De ahí la importancia de detenerse en las categorías que finalmente determinarán una situación de enfoque hacia el modo hermenéutico de interpretar. Se mantiene la propuesta de arribar a la hermenéutica de lo ausente que permita mirar e interpretar lo que podría mantenerse oculto.

Los entrelaces que se dan en una sociedad determinada por sus prácticas culturales y decisiones políticas que los sujetos proponen y ejecutan como políticas públicas que impactan a los ciudadanos, contienen en sí factores que al permanecer ocultos se convierten en invisibilizados a la mirada de la generalidad de los sujetos que conforman una sociedad.

Los fenómenos sociales albergan en su interior esos factores que en el discurso 
pasan como inexistentes, estos podrían ser intenciones verdaderas, ocultas tras un lenguaje que permite la opacidad de una realidad presentada. Un ejemplo son las políticas públicas estructuradas con la aparente finalidad de ir al encuentro de relaciones de equidad para los sectores sociales y son realmente un enfoque que favorece a grupos de dominación. La realidad se traduce en la espera de mejores formas de vida para las clases desprotegidas y el alejamiento constante de las posibilidades, albergando en sus intersticios lo invisibilizado.

Las estructuras creadas por la sociedad presentan una constante en términos de sistemas de inequidad, difieren en buena medida de los sistemas democráticos deseables para la creación de relaciones con posibilidades de construir alteridad desde la formación de ciudadanos. "Si hubiera que definir la democracia podría hacerse diciendo que es la sociedad en la cual no sólo es permitido, sino exigido, el ser persona" (Reyes Mate, 2010:4). Ser persona concebido como el sujeto activo que participa y es tomado en cuenta para el desarrollo pleno de sus capacidades como ciudadano.

Así, la búsqueda de formas interpretativas me ha llevado al análisis teórico de filósofos como Walter Benjamín formado en la Escuela de Frankfurt, productora de la teoría crítica que sustenta la Pedagogía Crítica, cuyo principio es la emancipación del sujeto.

Benjamín posiciona abiertamente en el análisis de las causas que propician en la sociedad, inequidad por grupos de poder y grupos de oprimidos por el mismo, plan- teando la necesidad de detectar e interpretar los fenómenos sociales basados en esta situación y enfatizando la posibilidad de interpretar desde los más pequeños fragmentos visibilizados en la deconstrucción del fenómeno mismo y que parecieran inservibles.

También plantea que el investigador habrá de desarrollar un trabajo de "trapero", es decir, tomar en cuenta como un factor de importancia lo que pareciera no tener ninguna utilidad y formar parte de los considerados "desechos" como una forma de dar vida a lo que en el pasado tuvo un significado que forma parte del olvido, plantea pues una manera de dar vida al pasado desde la luz del presente.

La importancia radica en revisar las posibles causas que determinan ciudadanos prestos a dar continuidad a estructuras sociales que marcan divisiones tales que se constituyen en un mundo de inequidad como lo plantea el filósofo español Reyes Mate, cuya propuesta retoma y analiza la necesidad de mirar los pequeños fragmentos que componen un fenómeno, contribuyendo a su edificación y mantenimiento como hechos naturalizados por una sociedad que los ha convertido en cotidianeidad. Es ahí donde encuentro un estrecho vínculo entre la Pedagogía Crítica y la interpretación desde la hermenéutica de lo ausente.

Reyes Mate centra su filosofía - que con toda actualidad recoge el pensamiento de Walter Benjamín-, en enfatizar la necesidad de mirar al pasado desde procesos hermenéuticos y traer al presente los fragmentos que componen los fenómenos sociales 
que desde la construcción de una cultura de poder edifica las políticas que regulan la vida social atendiendo intereses que lo protegen y a su vez desprotegen a los oprimidos que se constituyen en las mayorías. El pensador español interpreta la teoría de Benjamín y rescata la posibilidad de mirar la historia desde un punto de vista que permita tomar en cuenta lo que ha quedado en el pasado y contiene los elementos requeridos para comprender de una mejor manera el presente que sin duda presenta consecuencias en sus formas de vida y formación como ciudadanos.

El historiador benjaminiano no busca conocer mejor el pasado, sino transformar el presente. Pero esa voluntad de cambio sería imposible si el presente fuera inamovible, es decir, si la dominación del hombre sobre el hombre formara parte de la naturaleza de las cosas. Esa tentación, en la que a veces caen representantes de la Teoría Crítica, no la comparte Benjamín (Reyes Mate 2009 p. 105).

Es esa parte de la Teoría Crítica que me parece debe ser fortalecida por la hermenéutica de lo ausente. Es decir, mientras se siga tomando como única la versión que recibimos de la historia con visiones únicas e inamovibles en las que algunos sujetos son presentados como triunfadores y otros invisibilizados, seguirá el sujeto en espera de emanciparse de la dominación.

Reyes Mate detenta una orientación hacia la búsqueda permanente de equidad, de abatimiento de los grupos de poder. Es allí donde cabrían propuestas para fortalecer los sistemas de relaciones existentes que se han convertido en conductos que entrelazan decisiones políticas que ponderan el poder que a su vez vitaliza una cultura de dominación en la que los ciudadanos se ubican como dominantes y oprimidos.

La reflexión surgida sobre los problemas que en la actualidad forman parte de la sociedad, se han enfocado hacia las formas interpretativas mencionadas, ahí nace la necesidad de una hermenéutica que haciendo uso de ese lenguaje que se presenta sin confines, dé alcance a los pequeños fragmentos que de alguna forma permanecen en la invisibilidad de los fenómenos sociales y se han convertido en ausentes. Se requiere para esto una pedagogía que propicie el diálogo y la crítica.

Al analizar las propuestas de Walter Benjamín y Reyes Mate sobre la intención de fijar la mirada en pequeños fragmentos que parecieran inservibles y por lo tanto permanecen ausentes a la mirada que no escudriña, cobra sentido; es decir, se piensa en una hermenéutica que proporcione toda la libertad de lenguaje pensado como el ser mismo, que des-cubra esos factores que han quedado ocultos, ausentes y que forman parte de la realidad. Allí se encuentra La hermenéutica de lo ausente cuyo principal aliado es la mónada, que desarrolla la capacidad de llevar la singularidad a una generalidad, ¿cómo sería? La interpretación tendría que desnudar detalles que podrían conducir al encuentro de intenciones verdaderas ocultas en un discurso plagado de intencionalidades que no necesariamente son planteadas, pero forman parte del entramado político, social y cultural que en la actualidad genera las problemáticas del presente con origen en decisiones que han tenido lugar en el pasado y han sido con- 
sideradas parte del olvido y sin embargo, han dado lugar a esos sistemas de relaciones en los que reinan las relaciones de poder en las que la formación del ciudadano es fundamental; ¿qué ocurre en el sistema educativo para que los ciudadanos miren como naturalizado el hecho de pertenecer a un grupo o a otro?

La tarea de la hermenéutica de lo ausente no es sencilla, tendrá que fijar la mirada en esos considerados pequeños o grandes detalles "inservibles".

¿Qué podríamos encontrar detrás de un discurso dado como si su única intención fuera la procuración de equidad? Quizá un discurso que al mirarse como el ser mismo, denote esos reflejos que nos lleven a pensarlos como rastro que ubica huellas en el tiempo, y que además son parte inherente a las prácticas docentes como medio principal para allegar un discurso que impacta la formación de ciudadanos.

La propuesta consiste en desarrollar un proceso que implique asumir una actitud hermenéutica, desarrollar la capacidad de mirar lo no expuesto, lo que ha sido llevado a lo ausente como si no tuviera existencia y se convierte en la piedra angular que da vida a diferentes fenómenos sociales que afectan a los sujetos que han sido formados como los ciudadanos que acatan su condición como si no hubiera posibilidades de una transformación cultural.

Heidegger en su teoría sobre la verdad lo plantea como aletheia, desocultar lo oculto en cada cosa, en este caso lo implícito en el lenguaje con sus diferentes acepciones, en un discurso que no es congruente con la realidad.
Ver un ente sacándolo del "estado de oculto" en su estado de "no oculto" ("estado de descubierto") [...] significa "la cosa misma", lo que se muestra. [...] La verdad (el "estado de descubierto") tiene siempre que empezar por serles arrebatada a los entes. Los entes resultan arrancados al "estado de ocultos". El "estado de descubierto", fáctico en cada caso es siempre, por decirlo así, un robo. (Heidegger, 2002:243).

Si el ciudadano adquiere consciencia de las posibilidades de transformación cultural, desde la consciencia de lo oculto en su formación, estará dando un paso a una mejor construcción de sistemas de relaciones en los que la alteridad haga de los ciudadanos su forma de vida.

Arribar a una hermenéutica que permita mirar lo que ha sido convertido en ausencia, encuentra sustento también en el pensamiento del filósofo argentino Ricardo Forster, quien expone sus propuestas que implican la reflexión acerca de los sujetos desprotegidos al interior de los grupos sociales; sus pensamientos convergen en la importancia del otro. El planteamiento entonces radica en des-cubrir, desocultar desde un proceso hermenéutico, los factores que se convierten en piedra angular de los fenómenos que componen esos entrelazos de la sociedad contemporánea y sus problemáticas.

La hermenéutica de lo ausente da cuenta de esas ausencias, de eso no expuesto y además considerado sin importancia, pero con una fuerte influencia en lo que ha sido la formación del ciudadano actual desde el lenguaje. 
Los idiomas -sostiene Steiner- son organismos vivos. Infinitamente complejos, pero organismos a fin de cuentas. Contienen cierta fuerza vital, cierto poder de absorción y desarrollo. También pueden experimentar la decadencia [...] El lenguaje que configura el pensamiento, que le ha abierto el mundo al hombre, también puede servir para embrutecerlo. El engranaje mágico de las palabras esconde potencialidades divergentes, es poseedor de un fondo cuya profundidad se nos escapa. (Forster, 2011:21).

Mirar la profundidad y el impacto del lenguaje en la formación de ciudadanos se torna una situación que requiere sensibilidad para observar que el proceso educativo tendría que incorporar una actitud hermenéutica, que despliegue el engranaje categorial que logre llevar al centro de la discusión lo que podría representar el origen de un ciudadano formado para integrar los grupos sociales que sostienen toda una estructura, en la que existen inequidades que terminan por ser concebidas como naturalizadas, lo que impide que los factores que han permanecido ausentes lo sigan estando, si no media una interpretación como la propuesta por la hermenéutica de lo ausente y la Pedagogía Crítica.

\section{Bibliografía}

Benjamin, W. (2012). Ensayos escogidos. México, México: Coyoacán.

Forster, R. (2011). La muerte del héroe. Buenos Aires, Argentina: Ariel.

Forster, R.(2012). Benjamin, una introducción.Buenos Aires, Argentina: Quadrata.

Heidegger, M. (2002). El Ser y el Tiempo. México, México: Fondo de Cultura Económica.

Reyes, M. (2009). Medianoche en la historia. Barcelona, España: Trotta.

Reyes, M. (2010). Memoria histórica, reconciliación y justicia. Anthropos: 3-20. 